ARTICLE HISTORY: Received: April 4, 2021 Accepted: May 25, 2021 Published: June 3, 2021

УДК: $159.9 .01(575.2)$ ( 04)

К ВОПРОСУ О СУЩНОСТИ МЕНТАЛИТЕТА

Стамова Рахат Дуйшенгуевна.

Д.филос.н., профессор

Садыкова T.М.

(аспирант)

Отдел сочиальной философии, эстетики и этики

Института философии,

права и сочиально-политических исследований

им. А. А. Алтымышбаева НАН КР

\title{
TO THE QUESTION OF THE ESSENCE OF MENTALITY
}

\author{
Stamova Rakhat Duishenguevna, \\ D. Philos. n., Professor \\ Sadykova T. M. \\ (graduate student), \\ Department of Social Philosophy, \\ Aesthetics and Ethics Altymyshbayev \\ Institute of Philosophy, \\ Law and Socio-Political Studies \\ of the National Academy of Sciences \\ of the Kyrgyz Republic \\ тел.: +996 (550) 149908
}

\begin{abstract}
Аннотация. В статье рассматривается ряд черт менталитета, составляющих его сущность. Поведение и жизнедеятельность как каждой отдельной личности, так и социальных групп, общества в целом определяются экономической и политической мотивацией и целесообразностью, но не ограничиваются ими, а выстраиваются на некоторой духовно-психологической основе, включающей в себя помимо прочего и весь предшествующий опыт, и то или иное восприятие действительности, и ценностные суждения и т.д. Данное обстоятельство побуждает философов при оценке тех или иных общественных явлений и процессов обращаться к такому феномену, как менталитет, или ментальности, поскольку менталитет, составляя ядро личности и группы и отражая главные противоречия общества, определяет конкретный культурный уровень, характер и направление, программу индивидуальных и коллективных действий.

Abstract. The article considers a number of features of the mentality that make up its essence. The behavior and life activity of each individual, social groups, and society as a whole are determined by economic and political motivation and expediency, but are not limited to them, but are built on a certain spiritual and psychological basis, which includes, among other things, all previous experience, and this or that perception of reality, and value judgments, etc. This circumstance encourages philosophers to turn to such a phenomenon as mentality when evaluating certain social phenomena and processes, since mentality, forming the core of the individual and group and reflecting the main contradictions of society, determines the specific cultural level, nature and direction, and program of individual and collective actions.

Ключевые слова: менталитет, сущность менталитета, культура, взаимосвязь культуры и менталитета.

Keywords: mentality, essence of mentality, culture, relationship between culture and mentality.

Невозможно достоверным образом вскрыть, постигнуть закономерности общественно-исторического процесса, органической частью которого является культура, и прогнозировать дальнейший его ход, без достаточно глубокого знания менталитета. Те или иные культурные процессы не только происходят в пределах ментального поля, но и в целом определяются им. С другой стороны, те или иные культурные изменения, тем более имеющие масштабный, стремительный и радикальный характер, неизбежно приводят к трансформации ментального поля, в котором формируются и действуют люди - носители менталитета. Ментальное поле образует то, что можно определить как «дух культуры», ее тип, своеобразие. Под постоянным воздействием ментального поля в том или иному обществе образуется культура таковая со всеми ее специфическими чертами, определяемыми в конечном счете свойствами этого ментального поля. Правильное осмысление и учет
\end{abstract}


множества ментальных специфических черт индивидов, групп лиц и целых народов позволяет наиболее эффективным образом выстраивать свои действия с снижать уровень конфликтного взаимодействия на всех возможных уровнях.

Элементарной частицей, если так можно выразиться, ментального поля является менталитет, задающий все его основные свойства, и поэтому для того, чтобы понять взаимосвязь между ментальным полем и культурой, их обоюдную зависимость и характер взаимного влияния, необходимо в первую очередь разобраться в том, что представляет собой менталитет, ментальность.

Термин «менталитет» первоначально появился в пределах исторической науки, но в дальнейшем стал активно употребляться в социологии и психологии, пока не попал в поле зрения философии. По мере проникновения понятия «менталитет» в различные научные дисциплины само понятие эволюционировало, обрастая новыми гранями, значениями и смыслами. И поэтому в зависимости от того, представитель какой конкретной науки использует данный термин, категорию, изменяется смысл последней, которая может также преображаться в зависимости от контекста.

Часть специалистов ставят знак тождества между менталитетом и индивидуальным либо общественным сознанием или совокупностью психических особенностей субъекта [1, с. 15]. Другая часть, представляющая философскую науку, придерживается мнения, что менталитет представляет собой определенные элементы, части или уровни сознательного и бессознательного в индивидууме [2, с. 315-316]. Так, В.П. Визгин определяет менталитет как «глубинный уровень коллективного и индивидуального сознания, включающий и бессознательное; относительно устойчивая совокупность установок и предрасположенностей индивида или социальной группы воспринимать мир определенным образом» [3, с. 525]. И, наконец, третья группа специалистов-психологов считает, что менталитет в его реальном воплощении есть не что иное, как особенности сознания либо психики [4, с. 24].

Каждое из выше приведенных пониманий, представлений о менталитете раскрывает или, точнее, имеет дело с определенной его гранью, аспектом, набором свойств. Для нас наибольший интерес, по понятным причинам, представляет философская трактовка менталитета. Однако она, учитывая интересующий нас конкретный культурный контекст, и воздействие культурного поля на ментальное и наоборот, недостаточна. Поэтому приведем еще два определения, с одной стороны, дополняющих представление о менталитете, а с другой - вписывающих его в культурный контекст.

Менталитет (от лат. mens - душа, дух, ум) - склад ума, совокупность умственных, эмоциональных и культурных особенностей, а также ценностных ориентаций и установок, свойственных той или иной социальной либо этно-национальной группе, как и целому народу [5].

Менталитет в его реальном воплощении и проявлении представляет собой определенную совокупность представлений, переживаний, жизненных принципов, норм и установок людей, определяющее их общее восприятие и отношение к мира. Такое понимание менталитета позволяет трактовать его и как проекцию ментального поля, на основе которой возникает и функционирует культура, на сознание и психику людей.

Сущность менталитета, функционирующего в пределах определенного ментального поля и культурного пространства, проявляется в ряде его особенностей, воплощений, предметных отражений, выражений.

Во-первых, менталитет, какой бы спецификой он не был бы наделен той или иной социальной группы, народа, в любом случае отражает определенные специфические черты, особенности конкретного типа культуры, a с ними неизбежно и определенный специфический образ мыслей, сложившийся в течение относительно длительного времени у людей, сформировавшихся и существующих в пределах данной культуры. К примеру, кровная месть считается в современных условиях свойством, особенностью менталитета, присущей для архаической культуры, по большей части сошедшей с исторической сцены. Суть в том, менталитет, ментальность является культурно зависимой, культурно определяемой величиной, константой, производной, или, другими словами, конкретное содержание ментальности определяется конкретным содержанием культуры, и в силу в первую очередь именно культурного различия возникает и поддерживается ментальное различие, и чем сильней и очевидней культурное различие народов, тем, как правило, сильнее их различие менталитетов.

Во-вторых, менталитет, как и все в этом мире, есть то, что возникло, существует и преобразуется во времени, т.е. он представляет собой исторически обусловленный продукт, результат, явление, феномен, из чего следует, что те или иные социально-экономические трансформации, происходящие в обществе, и практически любая эволюция культуры независимо от того, в каком направлении она происходит и ее масштабов, имеют своим следствием изменение менталитета. Но учитывая то обстоятельство, что социально-экономические и культурные трансформации происходят в реальной жизни сравнительно медленно, то изменение менталитета происходит столь же медленно. Менталитет не следует отождествлять с кратковременными изменениями настроений, царящих в обществе, колебаниями в какую-либо сторону общественного мнения, эмоциональными всплесками, порывами, способными охватить большое количество людей, даже все общество, народ. В этом отношении менталитет характеризуется относительной устойчивостью, стабильностью, консервативностью. Предшествующий исторический опыт свидетельствует о том, что он во всяком случае мог сохраняться практически в неизменном виде в течение целых исторических эпох. И, как говорит тот же опыт, 
преобразование менталитета происходило по причине достаточно глубоких и масштабных культурных изменений, и чем сильнее были последние, тем существеннее были ментальные перемены. В данной связи следует указать на то, что одним из фундаментальных свойств истории человечества является такая ее черта, как постоянное ускорение социального времени, которое поначалу, в эпоху первобытности практически была тождественна физическому времени. Вот что, к примеру, пишет об этой эпохи, длившейся, как минимум, несколько сот тысяч лет, религиозный мыслитель ХХ века А.В. Мень: «Сравнивая наскальную ориньякскую живопись, относящуюся примерно к 25-му тысячелетию до н. э., и фрески Сахары 6-го тысячелетия, мы видим все один и тот же мир: угон скота, охота на диких животных, праздники, магические пляски женщин и воинов» $[6$, c. 62].

Все первобытные общества, где бы они не существовали, в типологическом и, судя по приведенной нами цитате, в ментальном отношении представляли собой если не одно и то же, то во всяком случае очень близкое, похожее друг на друга. Все археологические и этнографические данные говорят в пользу того, что для всех первобытных сообществ были характерны такие основополагающие черты, как общинная собственность на орудия труда и территорию обитания; коллективный характер труда, обусловленный чрезвычайно низким уровнем развития производительных сил; практически абсолютная зависимость от внешней природной среды; уравнительный характер распределения среди членов общины продуктов труда и природы. Несмотря на то, что в первобытную эпоху, иначе определяемому как доисторическая, любые изменения совершались крайне медленно, они тем не менее происходили. И благодаря именно этим изменением на определенном этапе своего развития человечество вошло в эпоху первых цивилизаций. И именно с этого момента, исторического периода социальное время с достаточной очевидностью стало ускорять свой ход, словно отрываясь от физического. Весьма красноречивый пример того, насколько стремительно убыстряется социальное время, приводится в труде известного американского философа и футуролога, одного из основоположников концепции постиндустриального или, как сейчас принято говорить, информационного общества Э. Тоффлера «Шок будущего», опубликованном в 1970 году, т.е. пятьдесят лет назад. Э. Тоффлер писал, в частности: «Если последние 50 тысяч лет существования человека измерить количеством поколений, жизнь каждого из которых длилась в среднем около 62 лет, то в общей сложности мы получим приблизительно 800 поколений, 650 из которых прожили свою жизнь в пещерах. При этом при жизни лишь последних 70 поколений стало возможным, благодаря возникновению письменности, осуществлять действенную связь между поколениями. Только в течение жизни последних 6 поколений множество людей приобщилось к печатному слову. Лишь при жизни 4 последних поколений люди стали способны с достаточной точность измерять время. Только последние 2 поколения использую электромотор. А значительная часть всех материальных благ, с которыми мы сталкиваемся в повседневной жизни, было создано в течение жизни нынешнего, 800-го поколения...» [7, с. 17]

Имея в виду все это, можно утверждать, что менталитет изменялся приблизительно с той же стремительностью, с какой преобразовывалась материальная часть культуры. В этом, к слову сказать, состоит одно из основных противоречий и сложностей современной постиндустриальной эпохи: окружающий нас мир, создаваемый человеческими знаниями и трудом, трансформируется с такой скоростью, что менталитет фактически не успевает адаптироваться к новым условиям. И человек уже не соответствует ни быстро нарастающему объему и уровню вырабатываемых им же знаниям, ни новым требованиям, возникшим в преобразованном мире. Хотя, с другой стороны, менталитет, тем не менее, меняется значительно быстрее, чем даже в предшествующую индустриальную эпоху, не говоря уже о всех предшествующих.

В-третьих, менталитет является частью структуры психики конкретного человека по ходу вхождения, приобщения последнего к конкретной культуре. Каждая личность с младенчества обретает собственный менталитет, усваивая менталитет собственного народа, овладевая его языком, воспринимая принятые нормы морали и поведения, приспосабливаясь в ежедневной жизни к бытовым и прочим условиям, окружению и т.д. словом, усваивая те или иные элементы культуры этого народа. Формирующаяся с ранних лет ментальность индивида неизбежно вбирает в себя как общие принципы, установки этнической либо национальной культуры, так и отдельные ее моменты, связанные с вариативными ее особенностями и обусловленные конкретной культурной средой, в которой индивид существует, формируется как личность. Поскольку жизнь человека охватывает обычно сравнительно долгий срок и среда его обитания может существенно меняться его ментальность может также серьезно видоизменяться, что происходит, как правило, в связи с попаданием его в ментальное поле, связанное с новой во многих отношениях для него культурной средой, новыми культурными формами, проявлениями, что часто приводит с значительным психологическим изменениям, сдвигам.

В-четвертых, менталитет является тем, в чем индивидуальное, личное и общественное сливаются, образуют единое при невозможности разъединить их и отличить друг от друга, благодаря чему менталитет народа представляет собой не простую, элементарную сумму менталитетов отдельных его представителей, индивидов, a, по сути, их общим знаменателем, выражающим их общее состояние, качество, некоторое общее внутреннее содержание, а также внешний контур, границы, пределы каждого отдельного менталитета. Менталитет, таким образом, представляет собой одновременно как коллективный социальный феномен, выступающий в качестве 
самостоятельной, независящей от отдельных лиц социокультурной реальности, так и сугубо личностное явление, присущее психике, складу отдельной личности, человека.

В-пятых, менталитет, охватывая практически все стороны жизни индивида, укореняется в конечном счете в сфере в бессознательного, в самых глубинах его психики, и по этой причине его реальное содержание, как показывает опыт, далеко не всегда может осознаваться его носителями. Те или иные ментальные установки, черты и особенности обычно представляются индивиду чем-то настолько очевидным и само собой разумеющимся, что он, как правило, не склонен к их анализу, рефлексии и, совершая те или иные поступки, ведя себя каким-либо образом, часто не отдает себе отчета в том, почему он думает и находит нужным поступать так, а не иначе. Благодаря такой способности менталитета, его всеохватности, присутствию в бессознательном, формируется то, что в аналитической психологии принято определять как архетип, т.е. универсальные, присущие всем без исключения, исконные врожденные психические структуры, образующие содержание коллективного бессознательного, которое является также итогом длительного культурного воздействия.

Очевидно, что все вышеуказанные черты менталитета в той или иной мере связаны с культурным воздействием либо являются результатом длительного влияния культуры.

\section{Список использованных источников}

1. Душков, Б.А. Психосоциология менталитета и нооменталитета [Текст] / Б.А. Душков. - Екатеринбург: Деловая книга, 2002. - 448 с.

2. Кошовец, О.Б. Ментальность // Словарь философских терминов / Под ред. В.Г. Кузнецова. - М.: ИнфраM, 2004. - $731 \mathrm{c}$.

3. Визгин, В.П. Ментальность // Новая философская энциклопедия. - Т. 2. - М., 2001. - С. 525.

4. Петровский, А.В., Ярошевский, М. Г. Основы теоретической психологии [Текст] / А.В. Петровский, М. Г. Ярошевский. - М., 1998. - 528 с.

5. Менталитет [Электронный ресурс]. Режим доступа: https://ru.wikipedia.org/wiki/Менталитет

6. Мень, А. История религии: В поисках Пути, Истины и Жизни // В 7 т. - Т. 2: Магизм и Единобожие: Религиозный путь человечества до эпохи великих Учителей. - М.: СП «Слово», 1991. - 462 с.

7. Кукаркин, А.В. По ту сторону расцвета. Буржуазное общество: культура и идеология [Текст] / А.В. Кукаркин / Изд. 2-е. - М.: Политиздат, 1977. - 400 с.

\section{References}

1. Dushkov, B.A. Psikhosotsiologiya mentaliteta i noomentaliteta [Text] / B.A. Dushkov. - Yekaterinburg: Delovaya kniga, 2002. - 448 p.

2. Koshovets, O.B. Mental'nost' // Slovar' filosofskikh terminov / Pod red. V.G. Kuznetsova. - M.: Infra-M, 2004. $731 \mathrm{p}$.

3. Vizgin, V.P. Mental'nost' // Novaya filosofskaya entsiklopediya. - Vol. 2. - M., 2001. - p. 525.

4. Petrovskiy, A.V., Yaroshevskiy, M. G. Osnovy teoreticheskoy psikhologii [Text] / A.V. Petrovskiy, M. G. Yaroshevskiy. - M., 1998. - 528 p.

5. Mentalitet [Electronic resource]. Access mode: https://ru.wikipedia.org/wiki/Менталитет

6. Men, A. History of Religion: In Search of the Way, Truth and Life // In 7 vol. - Vol. 2: Magizm i Yedinobozhiye: Religioznyy put' chelovechestva do epokhi velikikh Uchiteley. - M.: SP «Slovo»,1991. - 462 p.

7. Kukarkin, A.V. Po tu storonu rastsveta. Burzhuaznoye obshchestvo: kul'tura i ideologiya [Text] / A.V. Kukarkin / Ed. 2nd.- M.: Politizdat, 1977. - 400 p. 